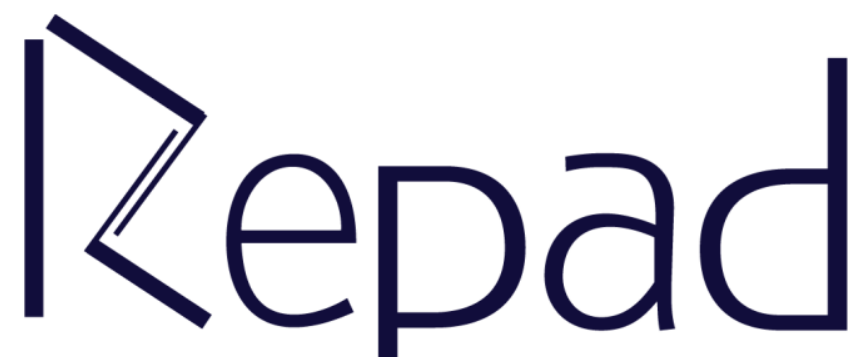

Vol. 2, n 2, AGOSTO/2018

Revista Estudos e

Pesquisas em Administração

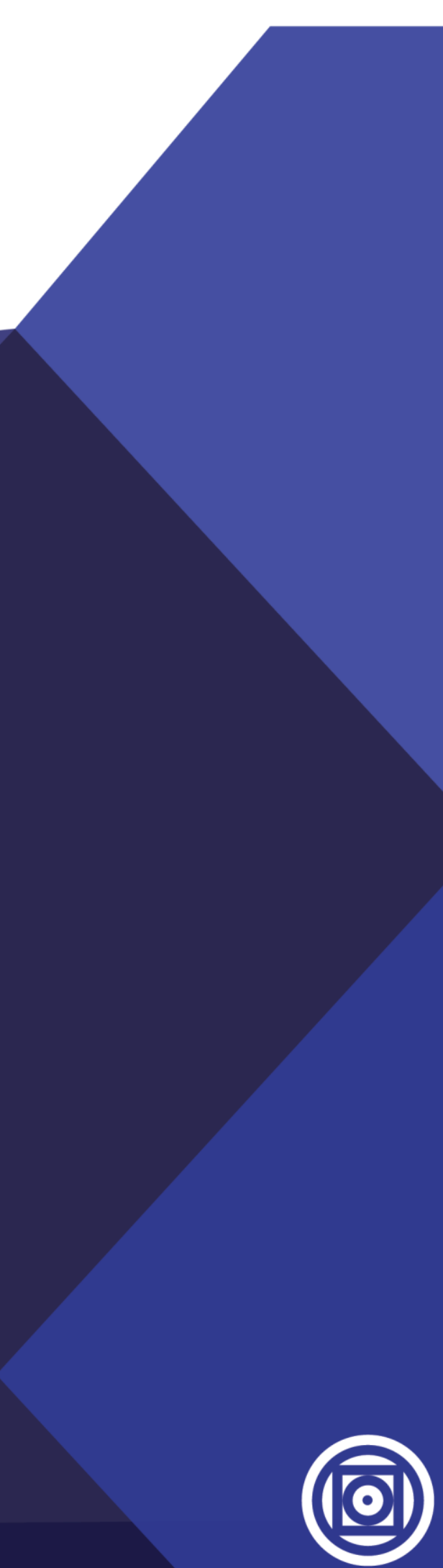




\section{AVALIAÇÃO DE UMA EMPRESA HOTELEIRA, COM BASE NOS MÉTODOS DOS MÚLTIPLOS DE MERCADO E DO FLUXO DE CAIXA DESCONTADO EM RONDONÓPOLIS-MT}

\section{VALUATION OF A HOTEL COMPANY, BASED ON THE METHODS OF RELATIVE VALUATION AND DISCOUNTED CASH FLOW IN RONDONÓPOLIS- MT}

João Bosco Arbues Carneiro Junior Universidade Federal de Mato Grosso https://orcid.org/0000-0001-7094-2245

Elahíne Santos de Moraes Universidade Federal de Mato Grosso https://orcid.org/0000-0003-1994-3773

Ramon Luiz Arenhardt Universidade Federal de Mato Grosso https://orcid.org/0000-0002-8990-3577

Sofia Ines Niveiros Universidade Federal de Mato Grosso https://orcid.org/0000-0001-6547-5881

\section{RESUMO}

O propósito desta pesquisa é proporcionar a compreensão da importância da avaliação de empresas, expondo seus variados métodos. A interrogação norteadora é: quais os valores estimados para a avaliação de uma empresa do ramo de hotelaria, utilizando as metodologias dos múltiplos de mercado e do fluxo de caixa descontado? O objetivo da pesquisa é estimar o valor da empresa utilizando estas duas metodologias. Na fundamentação teórica apresenta-se uma visão geral dos diversos modelos de avaliação de empresas e seus pressupostos. A metodologia é caracterizada como descritiva, estudo de caso e quantitativa e amostra é não probabilística. O objeto de estudo é um hotel situado no Distrito Industrial do município de Rondonópolis, no qual foram abordados os critérios de múltiplos de mercado e fluxo de caixa descontado, a fim de sugerir o real valor da empresa. Encontraram-se discrepâncias nos resultados de avaliação diante dos métodos utilizados, no qual ressaltou a superioridade do fluxo de caixa descontado por se aproximar mais da realidade em função de considerar o valor do dinheiro no tempo. Conclui-se que a pesquisa foi relevante aos proprietários da empresa, pois por visualizaram o valor da sua organização e identificaram qual melhor método representou esses valores.

Palavras-chave: Avaliação de empresa; Fluxo de caixa descontado; Hotel

\section{ABSTRACT}

The purpose of this research is to provide the understanding of the importance of the evaluation of the company, by exposing their varied methods. The guiding question is: what are the estimated values for the evaluation of a hotel business, using the methodologies of market 
multiples and discounted cash flow? The objective of the research is to estimate the value of the company using these two methodologies. The theoretical basis presents an overview of the various models of corporate assessment and their assumptions. The methodology is characterized as descriptive, case study and quantitative and sample is non-probabilistic. The object of study is a hotel located in the Industrial District of Rondonópolis, in which the criteria of market multiples and discounted cash flow were approached, in order to suggest the real value of the company. Found discrepancies in the evaluation results in relation to the methods used, in which it emphasized the superiority of discounted cash flow because it came closer to reality because of considering the value of money over time. It was concluded that the research was relevant to the owners of the company, because they visualized the value of their organization and identified which best method represented these values.

Keywords: Valuation; Discounted cash flow; Hotel.

\section{INTRODUÇÃO}

A avaliação empresarial resulta na análise da empresa, do seu histórico de resultados, do seu mercado e principalmente das suas perspectivas de crescimento. A relevância de realizar a avaliação tem como objetivo obter um valor de referência para negociações e operações entre entidades, como na criação do valor das ações, realizada através do retorno do capital investido, no reinvestimento do dinheiro, nos investimentos superiores ao custo do capital. (CORNELL, 1993; DAMODARAN, 2009).

Existem diversos modelos de avaliação que possuem pressupostos e níveis variados de subjetividade diferentes, contudo o objeto avaliado e o objetivo da avaliação que definem o melhor modelo. Os principais modelos são: balanço patrimonial, demonstração de resultado, goodwill, fluxo de caixa descontado e criação de valor. (FERNÁNDEZ, 2001; AMBROS; SCHNORRENBERGER, 2014).

Cunha e Lapeña (2007) realizaram uma pesquisa com 300 auditores independentes brasileiros, enquanto Martelanc et al (2005), consultaram 29 profissionais da área de fusões e aquisições e private equity, dos principais bancos de investimento e consultorias financeiras do Brasil, as duas pesquisas identificaram que o modelo de avaliação empresarial mais utilizado é Fluxo de Caixa Descontado.

A metodologia do Fluxo de Caixa Descontado (FCD) tem vantagens sobre os demais modelos de avaliação por ser mais completa, pois detém todos os critérios essenciais para visualizar o valor real de uma entidade. Este modelo adota como base de cálculo o valor econômico de uma empresa, ou seja, avalia os ativos pela riqueza econômica expressa a valor presente dimensionada pelos benefícios operacionais de caixa esperados no futuro e descontados por uma taxa de atratividade que reflete o custo de oportunidade dos provedores de capital. (ASSAF NETO, 2012; ASSAF NETO; LIMA, 2011).

Entre os modelos de avaliação de empresas, também, destaca-se o de "múltiplos de mercado", ou simplesmente "múltiplos", que consiste em um método que se propõe a avaliar ativos com base nos preços de mercado de ativos similares ou comparáveis. (ASSAF NETO, 2012; COUTO; GALDI, 2012). Richardson, Tuna e Wysocki (2010) realizaram uma pesquisa entre analistas de mercado a qual concluiu que os métodos de avaliação mais utilizados são: múltiplos de lucro, fluxo de caixa descontado e múltiplos de patrimônio.

Dentro deste contexto, este trabalho foi desenvolvido através de um estudo de caso em uma empresa hoteleira situada em Rondonópolis - MT, abordando os critérios de múltiplos de 
mercado e pelo fluxo de caixa descontado, devido ao alto grau de aceitação de ambos os critérios. A questão que norteia esta pesquisa é: Como a utilização das metodologias de avaliação através dos múltiplos de mercado e fluxo de caixa descontado, podem determinar o valor estimado de uma empresa do ramo de hotelaria? Para responder definiu-se como objetivo geral do trabalho, estimar o valor de uma empresa do ramo de hotelaria utilizando as metodologias de avaliação do fluxo de caixa descontado e múltiplos de mercado.

O estudo justifica-se pela importância dos proprietários da empresa, pois a pesquisa verificará o montante real da sua organização, se os valores apresentados no balanço patrimonial não distinguem do mercado capitalista. Também é relevante, porque resultará em informações que em caso de eventuais negociações que possam surgir, através da análise, as operações terão subsídios de dados para que não gerem perdas de capital para a empresa, tanto para casos de vendas, fusões, quanto para apurar o montante que cada sócio tem sobre a mesma.

Pressupõe-se que com os testes da pesquisa, o método de avaliação dos múltiplos de mercado e fluxo de caixa descontado irão demonstrar resultados semelhantes para os valores da referida empresa, visto que segundo pesquisas similares realizadas por Martins (2001) e Penman (2005) independentemente da quantidade de metodologias de avaliação existentes, todas devem convergir para um mesmo valor.

\section{REFERENCIAL TEÓRICO}

\section{Avaliação de Empresas}

A abordagem de avaliação de empresas ou valuation foi desenvolvida com o intuito de designar o valor de uma organização, não somente para fins de venda, mas para possíveis negociações que terá esse valor como referência, também denominado valor justo de mercado. (MARTINS ET AL, 2001)

O modelo de avaliação de empresa não traz um resultado exato, é apenas uma previsão da realidade para a empresa realizar suas operações, o objetivo da avaliação é o de apurar o fair value, ou seja, o seu valor justo. Para definir este valor deve-se levar em consideração o valor presente dos benefícios econômicos futuros, descontados a uma taxa de juros que remunere o custo de oportunidade dos investidores. (ASSAF NETO, 2012).

Assim, observa-se que avaliar uma empresa não é uma tarefa fácil, mas é algo essencial para a vida de uma organização, devido as possíveis operações que possam ocorrer na mesma, como venda, fusões, aquisições, mercado de ações. Afim de não obter resultados negativos com essas respectivas operações, é necessário que o valor da empresa seja apurado.

Existem diversos modelos de avaliação, todos com certos pressupostos e níveis variados de subjetividade. (ASSAF NETO; LIMA, 2011; ASSAF NETO, 2012; MARTINS, 2001). No entanto, a Comissão de Valores Mobiliários (CVM 361, 2002), exige que nas ofertas públicas de aquisição de ações de companhia aberta, o valor econômico da empresa por ação seja calculado pela regra do fluxo de caixa descontado (FCD) ou por múltiplos.

Assim, a avaliação de empresas é apenas uma projeção do valor da mesma, uma estimativa não podendo ser considerado exato, para tanto existe o grau de risco da mesma. A seguir apresenta-se o motivo pelo qual alguns destes métodos não serão utilizados e a continuação mais detalhadamente os dois métodos de avaliação de empresas que foram utilizados para análise da empresa em estudo.

Fernández (2001) classifica os principais modelos de avaliação de empresas em seis grupos conforme Tabela 1. 
Tabela 1 - Principais métodos de avaliação de empresas

\begin{tabular}{|c|c|c|c|c|}
\hline $\begin{array}{c}\text { Balanço } \\
\text { Patrimonial }\end{array}$ & $\begin{array}{c}\text { Demonstração } \\
\text { de resultado }\end{array}$ & $\begin{array}{c}\text { Misto ou } \\
\text { Goodwill }\end{array}$ & $\begin{array}{c}\text { Fluxo de caixa } \\
\text { descontado }\end{array}$ & Criação de valor \\
\hline Valor contábil & Múltiplos & Clássico & Fluxo de caixa & EVA \\
V. Cont. & Valor dos lucros & Simplificado da & livre & Lucro \\
Ajustado & Múltiplos de & União Européia & Dividendos & econômico \\
Valor de & faturamento & Peritos & Equity cash flow & Valor de caixa \\
liquidação & Outros modelos & Contábeis & Capital Cash & adionado \\
Valor & de múltiplos & Renda & value & Cash Flow \\
substancial & & Abreviada & Modelo de & returno n \\
& & Outros Modelos & dividendos & Investmente - \\
& & & Adjusted Present & CFROI \\
& & & Value - AVP & Outros modelos \\
& & & Outros modelos & \\
& & & \\
& & & \\
& & &
\end{tabular}

Fonte: Adaptado de Fernández (2001).

Os métodos baseados no Balanço Patrimonial utilizados na avaliação de empresa é o que mais reflete a informação contábil, devido ao fato de não passar por ajuste. Em função deste não considerar o dinheiro no tempo, e possível crescimento da empresa, e sim apresenta somente dados históricos, o modelo considera-se não eficaz (MARTINS, 2001; ASSAF NETO, 2008)

O método de avaliação de empresas com base no patrimônio líquido é válido para obter informações referente aos ativos da organização, porém não na capacidade de geração de resultados futuros. (MARTINS, 2001) Mesmo com uma forma simples de ser realizada e de fácil compreensão não são muito aceitas no mercado, devido ao fato dos seus usuários na maioria das vezes estarem interessados nos futuros resultados que a empresa irá realizar e não nos investimentos feitos pelos acionistas.

O valor de liquidação é considerando o valor como se a organização fosse ser liquidada. É o resultado do valor de venda dos seus ativos juntamente com o pagamento de todas as obrigações, ajustando assim o resultado pelas despesas de liquidação e encerramento. Portanto o valor de liquidação é uma base para o valor o mínimo que a empresa poderá ser vendida, pois não há lógica a mesma ser liquidada com valor inferior ao seu fechamento, portanto o mesmo não é eficaz em situações de continuidade. (ASSAF NETO, 2008; MÜLLER; TELÓ, 2003)

Outro o método de avaliação de empresas pelo Balanço Patrimonial é o modelo do valor substancial, este é representado pelo cálculo do investimento que deveria ser feito para constituir uma empresa em idênticas condições, as da empresa que está sendo avaliada. (FALCINI, 1995; MÜLLER; TELÓ 2003). Neiva (1999) critica esse modelo e ressalta que é difícil criar uma empresa em condições semelhantes de funcionamento como daquela que se pretende adquirir.

O goodwill representa o valor da parte intangível da empresa. O valor do goodwill pode ultrapassar o valor contábil ou valor contábil ajustado da empresa. Alguns valores de intangíveis não aparecem na contabilidade, no entanto, contribuem para atribuir valor a empresa. (SCHMIDT; SANTOS, 2002). Um dos grandes inconvenientes da mensuração do goodwill reside na dificuldade de mensuração de seu valor. (MÜLLER; TELÓ, 2003).

O modelo clássico de goodwill estabelece que o valor de uma empresa é determinado pela soma dos seus ativos líquidos (a valor de mercado ou a valor substancial) e do valor de seu goodwill. Para esse modelo, o goodwill é avaliado como um multiplicador da receita líquida da 
empresa. Caso o valor total da empresa excede a soma dos valores dos ativos avaliados separadamente, este excesso deve representar o valor de todos os fatores positivos que tornam a empresa mais valorizada (considerada como um todo) que a soma dos ativos específicos. (NEIVA, 1999).

O modelo simplificado da União Européia, também é conhecido como Abbreviated goodwill income method e é obtido por capitalização, pela aplicação do coeficiente de goodwill, que representa um superlucro igual à diferença entre a receita líquida e os investimentos dos ativos. Um outro modelo, o dos peritos contábeis europeus, o valor total de uma empresa é igual ao valor dos ativos líquidos reavaliados (valor substancial) somado ao goodwill. (MÜLLER; TELÓ, 2003).

\section{Múltiplos de Mercado}

Entre os métodos de avaliação de empresas, um dos que se destaca é o de "múltiplos de mercado", também denominado "múltiplos", este propõe avaliar ativos com base nos preços de mercado de ativos similares ou comparáveis com o de outras empresas semelhantes cotadas em bolsas de valores. (ASSAF NETO, 2012). Richardson, Tuna e Wysocki (2010) realizaram uma pesquisa que concluiu que os métodos mais comumente usados entre analistas de mercado para a avaliação são respectivamente: múltiplos de lucro, fluxo de caixa descontado e múltiplos de patrimônio.

Uma dificuldade na utilização deste método é encontrar uma empresa similar à que será objeto de avaliação, mesmo que seja do mesmo ramo de atividade, as empresas podem se diferir uma da outra quanto ao risco, tamanho, perfil de clientes, tecnologia, poder de ganho futuro e entre outros. Mesmo assim o método é bastante utilizado, visto que esses problemas podem ser resolvidos facilmente. (ASSAF NETO; LIMA, 2011).

A facilidade de sua utilização está no fato de que para avaliar uma empresa basta aplicar um, ou alguns números-índices, os quais são calculados levando-se em consideração dois elementos: o valor de uma empresa semelhante e um valor de referência dessa mesma empresa, tal qual vendas, lucro líquido, EBITDA, patrimônio líquido, ativos etc (MARTELANC; PASIN; CAVALCANTE, 2005; ASSAF NETO; LIMA, 2011). Portanto, para realizar o método é necessário estabelecer um múltiplo.

\section{Fluxo de Caixa Descontado}

No mercado acionário, um dos métodos mais difundidos e aplicados para a determinação do valor de uma empresa é o fluxo de caixa descontado pelo seu rigor conceitual e coerência com a moderna Teoria de Finanças. (ASSAF NETO, 2008) A superioridade desta metodologia está relacionada com a capacidade que a empresa tem de geração de renda, é o método mais completo para avaliar uma empresa, pois considera o valor do dinheiro no tempo e representa o modelo mais utilizado pelos usuários, devido ao fato de seus resultados estarem mais próximo da realidade esperada. (MARTINS, 2001).

No método em questão o valor da empresa é determinado pelo valor presente dos fluxos de caixa dos acionistas e credores, descontados por uma taxa média que reflete seus respectivos riscos, ou seja, é possível apurar-se o valor de uma empresa com base em seus fundamentos financeiros expressos em seus fluxos de caixa. (ASSAF NETO; LIMA, 2011).

O modelo tem como base para avaliação o fluxo de caixa da empresa, onde são visualizadas todas as entradas e saídas de dinheiro. Assaf Neto (2012) afirma como são elaborados os modelos do fluxo de caixa descontado e como se chega ao valor venal da empresa, onde a base de avaliação do modelo são os fluxos de caixa, definidos em termos operacionais, dos quais se excluem os fluxos financeiros de remuneração do capital. Para avaliação 
econômica, os valores relevantes são os provenientes da atividade operacional da empresa, que devem estar disponíveis a todos os provedores de capital. Devem ser apurados dessa estrutura de entradas e saídas de caixa a riqueza líquida mantida no momento presente, ou seja, o valor da empresa, por isso esses fluxos operacionais devem ser projetados para determinado horizonte de tempo. (ZILLI, 2010)

Porém, no processo de avaliação não são consideradas somente os fluxos de caixa esperados, mas também como eles serão disseminados ao longo do tempo, além de levar em consideração a taxa de desconto aplicada.

Com base nessas informações demonstra-se como é desenvolvida a expressão genérica de cálculo, conforme Assaf Neto (2012):

$$
\begin{aligned}
& \text { Valor }=\underline{\mathrm{FCO}}+\underline{\mathrm{FCO}_{2}}+\underline{\mathrm{FCO}_{3}}+\ldots+\underline{\mathrm{FCO}} \\
& (1+\mathrm{K}) \overline{(1+\mathrm{K})^{2}}(1+\mathrm{K})^{3} \quad(1+\mathrm{K})^{\mathrm{N}}
\end{aligned}
$$

Onde:

Valor $=$ valor econômico (presente) do investimento;

$\mathrm{FCO}=$ ao fluxo de caixa operacional;

$\mathrm{K}=$ a taxa de desconto, que represente o custo médio ponderado de capital (WACC ou CMPC).

Copeland, Koller e Murrin (1996 apud GOULART, 2002) explicam que tanto credores quanto acionistas esperam ser remunerados pelo custo de oportunidade do investimento de seus recursos em uma determinada empresa, em vez de outra de risco semelhante.

Assaf Neto (2012) apresenta a fórmula para o cálculo do Custo Médio Ponderado de Capital (Weighted Average Cost of Capital - WACC):

$$
W A C C=k_{e} \frac{E}{D+E}+K_{d} \cdot \frac{D}{D+E}
$$

Onde:

$\mathrm{Ke}=$ custo do capital próprio;

$\mathrm{Kd}=$ custo efetivo das dívidas $=\mathrm{kd} \times(1-\mathrm{t})$;

$\mathrm{t}=$ somatório das alíquotas do imposto de renda (IR) e da contribuição social sobre o lucro

líquido (CSLL);

$\mathrm{E}=$ valor de mercado do capital próprio (equity);

$\mathrm{D}=$ valor de mercado das dívidas (debt);

Cerbasi (2003) define três elementos fundamentais para o uso do FCD: o fluxo de caixa projetado, o valor residual e a taxa de desconto.

Portanto, conclui-se que o melhor método de avaliação de empresas em comparação com os relacionados acima, é o modelo de fluxo de caixa descontado, pois se apresenta como o mais completo, demonstrando quanto a empresa irá gerar de riquezas futuras e é aceito pela maioria dos usuários, devido a várias metodologias utilizadas, além de objetivar a capacidade de geração de renda. É relevante destacar que os valores do FCD no estudo de caso apresentado por este artigo não se aplicam à avaliação do desempenho histórico, pois seus cálculos se baseiam em projeções.

\section{PROCEDIMENTO METODOLÓGICOS}

As tipologias da pesquisa que delinearam o trabalho se enquadram na característica de descritiva, estudo de caso e quantitativa. (BEUREN, 2010; MARTINS; THEÓPHILO, 2009) 
A amostra se define como não probabilística. Todas as informações necessárias para a aplicabilidade do projeto na respectiva empresa foram coletadas através do consultor da organização, cuja identidade será preservada. A pesquisa é caracterizada como teóricoempírica.

A base desta pesquisa científica é um hotel denominado HJ (nome fantasia), com mais de 15 anos no mercado, situado no município de Rondonópolis-MT. Tem uma estrutura de 35 apartamentos. A média de preços dos apartamentos é $\mathrm{R} \$ 150,00$ a diária, incluso o café da manhã, com check in e check out às 12:00hs.

A empresa é enquadrada como Empresa de Pequeno Porte (EPP) devido sua receita bruta anual estar entre 360 mil e igual ou inferior a 3,6 milhões de reais conforme consta na Lei Complementar $\mathrm{n}^{\circ} 139$, de 10 de novembro de 2011. Especificamente seu faturamento chega a $\mathrm{R} \$ 734.634,94$, seus custos e despesas totais nos últimos 12 meses foram de $\mathrm{R} \$ 318.424,60$. Entre as características da empresa destacamos: opta pelo regime de tributação do simples nacional; possui 8 funcionários registrados; apresenta um crescimento de $10 \%$ a.a., tendo em vista o acompanhamento das receitas; e aproximadamente $70 \%$ dos quartos são utilizados. Esta opera com recursos próprios, ou seja, não utiliza de endividamentos de longo prazo junto a bancos.

\section{ANÁLISE DOS RESULTADOS}

\section{Projeção de Fluxos de Caixa}

As projeções futuras de caixa são análises do passado para serem realizadas estimativas para o futuro, demonstram como supostamente a empresa irá se comportar no mercado, no que concerne a estimativas de vendas, recebimentos, pagamentos, necessidade de capital de giro, entre outros. Para ser realizada a respectiva projeção se utilizaram os prazos médios de pagamento e recebimento juntamente com o orçamento empresarial, após a empresa realizar esses procedimentos ela poderá desenvolver uma projeção de caixa para melhor administração de seus recursos, e conforme Tabela 2, o horizonte de projeção foi de 10 anos.

Tabela 2. Fluxo de caixa operacional (em R $\$$ - desconsiderando os centavos)

\begin{tabular}{l|l|l|l|l|l|l|l|l|l|l}
\hline & Ano 1 & Ano 2 & Ano 3 & Ano 4 & Ano 5 & Ano 6 & Ano 7 & Ano 8 & Ano 9 & Ano 10 \\
\hline Vendas & 1.390 .750 & 1.551 .825 & 1.729 .007 & 1.923 .908 & 2.138 .299 & 2.374 .128 & 2.633 .541 & 2.918 .896 & 3.232 .785 & 3.578 .064 \\
\hline (-) Custos & 556.300 & 620.730 & 691.603 & 769.563 & 855.319 & 949.651 & 1.053 .416 & 1.167 .558 & 1.293 .114 & 1.431 .225 \\
\hline (-) Despesas & 360.000 & 396.000 & 435.600 & 479.160 & 527.076 & 579.783 & 637.761 & 701.538 & 771.691 & 848.861 \\
\hline (=) EBIT & 474.450 & 535.095 & 601.804 & 675.184 & 755.903 & 844.693 & 942.363 & 1.049 .799 & 1.167 .979 & 1.297 .977 \\
\hline (-) Impostos & 176.347 & 210.272 & 236.528 & 287.239 & 322.027 & 364.428 & 407.672 & 495.628 & 553.776 & 623.298 \\
\hline (=) FCL & 298.102 & 324.822 & 365.276 & 387.945 & 433.875 & 480.264 & 534.690 & 554.170 & 614.203 & 674.678 \\
\hline
\end{tabular}

Fonte: Elaborado pelos autores (2016)

Esta projeção é estimada tendo em vista o período anterior a que empresa entre na maturidade, tanto que após a projeção é calculada a perpetuidade ou valor residual. Não existe bibliografia e/ou estudos que definem a quantidade exata de anos a serem projetados, sendo assim, neste estudo acredita-se que a empresa demorará 10 anos para entrar na fase madura quando seu fluxo de caixa tornar-se-á constante.

Conforme demonstrado nos cálculos, a receita foi estimada pelo ingresso das diárias, que é calculada estimando uma média de ocupação de $70 \%$ dos quartos existentes, ou seja, aproximadamente 25 quartos diários utilizados, no valor de $\mathrm{R} \$ 150,00$ cada. Com o passar dos anos há um acréscimo de $10 \%$ sob a receita estimada. O excedente da receita é através de vendas referente a bebidas, como água, refrigerantes, e também de salgadinhos, bolachas e derivados. 
O custo previsto foi registrado através dos gastos relativos ao consumo de energia, água, serviços de limpeza, e salários de funcionários diretamente ligados a hospedagem, totalizando um valor mensal estimado em aproximadamente $40 \%$ da receita bruta total, acompanhando assim o aumento da mesma. As despesas estimadas em $\mathrm{R} \$ 30.000 .00$ por mês, estão compostas pela folha salarial, café da manhã, telefone, e outros; estas crescem simultaneamente com o aumento da receita bruta. As alíquotas de imposto de renda e contribuição social são calculadas conforme tabela do simples nacional, o qual é estimado conforme a receita bruta anual.

\section{Estimativa do Custo de Capital}

Em todo projeto de investimento faz-se necessário estimar o custo de capital, que é uma taxa utilizada para verificar o valor do dinheiro no tempo. A estimativa do Custo de Capital verifica o retorno mínimo esperado para o investimento, no qual expõe o retorno exigido para empresa, o valor que a entidade precisa para suprir seu custo do capital. (ROSS, 2008; ASSAF NETO, 2012)

A empresa é EPP e não possui dívidas a longo prazo ou valores relevantes em seu passivo não circulante e também não comercializa ações. Arbitrou-se o seguinte valor para a estimativa do custo de capital: (a) Taxa Selic - representa a taxa livre de risco, ou seja, o investidor já possui este retorno garantido caso não deseje realizar nenhum investimento. A taxa era de 14,15\% a.a., conforme pesquisa realizada no Banco Central do Brasil e (b) $4 \%$ - este percentual foi dado pelo próprio empresário, pois o mesmo mencionou que estaria satisfeito se seu investimento obtivesse um retorno superior a $4 \%$ da Selic, sendo assim observa-se que a taxa determinada foi arbitrada porém segundo o que a teoria financeira ensina sobre tal assunto, que o custo de capital próprio deve levar em consideração um percentual livre de risco acrescido pelo prêmio pelo risco. Desta forma, classifica-se este percentual como o prêmio pelo risco de mercado. Levando em consideração as duas taxas, o custo de capital próprio estimado é de $18,15 \%$.

\section{Avaliação do Fluxo de Caixa Descontado}

No cálculo do fluxo de caixa operacional a empresa apresentou um aumento em sua receita em torno de $10 \%$, seu custo acompanhou o crescimento da receita e aumentou em $10 \%$ ao ano. As despesas foram $7 \%$, devido ao aumento das hospedagens com isso as despesas crescem juntas, pois é necessária uma manutenção maior para uma crescente quantidade de hóspedes. Vale aqui mencionar que todas estas informações foram coletadas através de entrevista com o proprietário do empreendimento. Para o cálculo do fluxo de caixa descontado, faz-se necessário encontrar o valor presente da perpetuidade (VPP), ou seja, o crescimento constante, logo abaixo segue uma fórmula para melhor exemplificação:

Valor presente da perpetuidade $=$

valor da perpetuidade

taxa de desconto do fluxo $-\mathrm{g}$

Onde:

$\mathrm{G}=$ é a taxa de crescimento constante

Valor da perpetuidade $=$ último fluxo de caixa livre

$V P P=\frac{674.678,59}{0,1815-0,1}=\frac{674.678,59}{0,0815}=8.278 .264,91$

A valor presente da perpetuidade $=\underline{8.278 .264,91}=1.561 \cdot 716,00$

$$
1,1815^{10}
$$


Fundamentado no exposto, segue, na Tabela 3, o cálculo da avaliação de empresa através do método do fluxo de caixa descontado, considerando o valor do dinheiro no tempo durante o período de 10 anos.

Tabela 3. Cálculo da Avaliação pelo método de Fluxo de Caixa Descontado

\begin{tabular}{|c|c|c|c|c|c|}
\hline Fluxo de Caixa Livre & Taxa & Período & Total & Perpetuidade & FCD \\
\hline $\mathrm{R} \$ 298.102,90$ & 1,1815 & 1 & $\mathrm{R} \$ 252.308,84$ & & \\
\hline $\mathrm{R} \$ 324.822,71$ & 1,1815 & 2 & $\mathrm{R} \$ 232.690,65$ & & \\
\hline $\mathrm{R} \$ 365.276,27$ & 1,1815 & 3 & $\mathrm{R} \$ \quad 221.472,74$ & & \\
\hline $\mathrm{R} \$ 387.945,45$ & 1,1815 & 4 & R\$ $199.083,73$ & & \\
\hline $\mathrm{R} \$ 433.875,60$ & 1,1815 & 5 & $\mathrm{R} \$ \quad 188.450,20$ & & \\
\hline $\mathrm{R} \$ \quad 480.264,99$ & 1,1815 & 6 & R\$ $176.554,41$ & & \\
\hline $\mathrm{R} \$ \quad 534.690,89$ & 1,1815 & 7 & $\mathrm{R} \$ \quad 166.366,82$ & & \\
\hline $\mathrm{R} \$ \quad 554.170,93$ & 1,1815 & 8 & $\mathrm{R} \$ \quad 145.939,86$ & & \\
\hline $\mathrm{R} \$ \quad 614.203,25$ & 1,1815 & 9 & $\mathrm{R} \$ \quad 136.901,62$ & & \\
\hline $\mathrm{R} \$ \quad 674.678,59$ & 1,1815 & 10 & R\$ $127.279,85$ & & \\
\hline \multicolumn{3}{|c|}{ Total Geral } & $\mathrm{R} \$ 1.847 .048,72$ & $\mathrm{R} \$ 1.561 .716,00$ & $\mathrm{R} \$ 3.408 .764,72$ \\
\hline
\end{tabular}

Fonte: Elaborado pelos autores (2016)

O Valor do FCD é R\$ 3.408.764,72 que é a soma do total do FCL de todos os períodos $\mathrm{R} \$ 1.847 .048,72$ mais o VPP a valor presente $\mathrm{R} \$ 1.561 .716,00$.

\section{Avaliação dos múltiplos de mercado}

Na avaliação de empresa através do método dos múltiplos de mercado, multiplica-se o valor do EBIT do ano 1, pelos múltiplos de mercado 5 ao 10. Este procedimento é feito com base em Titman e Martin (2010) que ensinam que a projeção da quantidade de anos a ser utilizada para o cálculo é estimada conforme a sensibilidade do avalista, sendo que, normalmente, varia entre 5 a 10 anos, conforme o tipo de atividade empresarial desenvolvida. Os dados são apresentados na Tabela 4.

Tabela 4. Cálculo da Avaliação pelo método dos Múltiplos de Mercado

\begin{tabular}{|c|c|c|}
\hline MÚLTIPLOS & EBIT ANO 1 & VALOR \\
\hline 5 & $474.450,00$ & $2.372 .250,00$ \\
\hline 6 & $474.450,00$ & $2.846 .700,00$ \\
\hline 7 & $474.450,00$ & $3.321 .150,00$ \\
\hline 8 & $474.450,00$ & $3.795 .600,00$ \\
\hline 9 & $474.450,00$ & $4.270 .050,00$ \\
\hline 10 & $474.450,00$ & $4.744 .500,00$ \\
\hline
\end{tabular}

Fonte: Elaborado pelos autores (2016)

O valor da empresa, através deste método, tem uma variação entre $\mathrm{R} \$ 2.372 .250,00$ a $\mathrm{R} \$$ 4.744.500,00, dependendo do múltiplo escolhido e designado pelo investidor.

\section{CONSIDERAÇÕES FINAIS}

Nesta pesquisa foi abordada a avaliação da empresa hoteleira designada HJ situada na cidade de Rondonópolis - MT. A avaliação foi realizada através dos métodos de FCD e múltiplos de mercado, a fim de demonstrar qual modelo representa mais próximo da realidade 
o valor da empresa, que poderá ser objeto de negociação futura e conhecimentos dos usuários das informações.

A hipótese da pesquisa partiu do pressuposto que o método de avaliação dos múltiplos de mercado e fluxo de caixa descontado demonstraria resultados semelhantes para os valores da referida empresa, porém esta afirmação foi rejeitada ao verificar a apresentação de resultados distintos entre os métodos de avaliação utilizados.

Como resultado do desenvolvimento do trabalho foi identificado através dos cálculos realizados a discrepância de resultados entre os modelos de fluxo de caixa descontado R \$ 3.408.764,72 e dos múltiplos de mercado de $\mathrm{R} \$ 2.372 .250,00$ a $\mathrm{R} \$ 4.744 .500,00$, devido ao fato do primeiro considerar o valor do dinheiro no tempo e a taxa de retorno, já o segundo ser apenas um múltiplo do valor do EBIT. Percebe-se que o valor da empresa através do método FDC, se concentra no centro na variação dos múltiplos de mercado, portanto nota-se que o método dos múltiplos tem variações significativas em seus valores dependendo do múltiplo a ser utilizado. Conclui-se a superioridade da avaliação pelo método do fluxo de caixa descontado, pois dentre todos pontos positivos, ele é o que mais chega a um resultado próximo da realidade por considerar o valor do dinheiro no tempo, ao contrário dos múltiplos que utiliza um múltiplo qualquer designado pelo investidor, consultor, para ser previsto o valor da empresa.

Nota-se a importância do presente estudo, tendo em vista que devido aos vários critérios existentes e que podem ser utilizados para o processo de avaliação de empresas, confirmou-se que o FCD produz um resultado mais fidedigno. Diante disto, os proprietários da empresa terão a informação que poderá ser útil numa possível negociação empresarial ou somente para fins de análise do desempenho empresarial.

Portanto a presente pesquisa científica foi de extrema relevância aos proprietários da empresa, pois por meio dela eles visualizaram o valor da sua organização e assim identificaram qual melhor método representou esses valores.

Sugere-se como possibilidade de novos estudos a aplicação dos modelos de avaliação patrimonial e avaliação pelo EVA®/MVA® com o intuito de verificar se estes trarão resultados semelhantes ao encontrado nesta pesquisa.

\section{REFERÊNCIAS}

AMBROS, M.G.; SCHNORRENBERGER, D. Avaliação de Empresas: Estudo com base nos métodos do balanço patrimonial e do fluxo de caixa descontado. In: CONGRESSO UFSC DE CONTROLADORIA E FINANÇAS E CONGRESSO UFSC DE INICIAÇÃO CIENTÍFICA, 5., 2014. Florianópolis. Anais eletrônicos... Florianópolis: UFSC, Disponível em: $\quad\langle$ http://dvl.ccn.ufsc.br/congresso/arquivos_artigos/artigos/960/20140428023933.pdf> Acesso em: 22 nov. 2016.

ASSAF NETO, A. Finanças Corporativas e Valor. $6^{\text {a }}$ ed. São Paulo: Atlas, 2012.

ASSAF NETO, A.; Lima, F. G. Curso de Administração Financeira. $2^{a}$ ed. São Paulo: Atlas, 2011.

BEUREN, Ilse Maria. Metodologia da Pesquisa Aplicável às Ciências Sociais. Como Elaborar Trabalhos Monográficos em Contabilidade: Teoria e Prática. $3^{\mathrm{a}}$ ed. São Paulo: Atlas, 2010. 
BRASIL. Lei Complementar $n^{\mathbf{0}}$ 123, de 14 de dezembro de 2006. Tabela do Simples Nacional. Brasília: Congresso Nacional, 2006. Disponível em: <http://www.planalto.gov.br/ccivil_03/leis/LCP/Lcp123.htm>. Acesso em: 20 out. 2016.

CERBASI, G. P. Metodologias para determinação do valor das empresas: uma aplicação no setor de geração de energia elétrica. Dissertação (Mestrado em Administração) Departamento de Administração. Universidade de São Paulo. São Paulo, 2003. 143 f. Disponível em: <http://www.teses.usp.br/teses/disponiveis/12/12139/tde-06092003122503/pt-br.php>. Acesso em: 20 out. 2016.

CORNELL, B. Corporate Valuation: Tools for Effective Appraisal and Decision Making. New York: Business One Irwin, 1993.

COUTO, C. G.; GALDI, F. C. Avaliação de empresas por múltiplos aplicados em empresas agrupadas com análise de cluster. RAM, Revista Administração Mackenzie, v. 13, n. 5, São Paulo. Universidade Presbiteriana Mackenzie. Walter Bataglia (Ed.), 2012. p. 135-170.

CUNHA, D. R.; LAPEÑA, J. A. A. Análisis de los modelos de valoración utilizados em la práctica: Un estudio con auditores independientes brasileños. Revista Universo Contábil, Blumenau, v. 3, n. 3, 2007. p.123-138.

CVM. Comissão de Valores Mobiliários. Instrução n. 361, mar., 2002. Disponível em: <http://www.cvm.gov.br/>. Acesso em. 18 set. 2016.

DAMODARAN, A. Avaliação de Investimentos: Ferramentas e Técnicas para a Determinação do Valor de qualquer Ativo. 2. ed. Rio de Janeiro: Qualitymark, 2009.

FERNÁNDEZ, P. Company valuation methods: The most common errors in valuation. Price water house Coopers Professor of Corporate Finance. Madrid. IESE Business School, 2001.

GITMAN, J. L. Princípios de Administração Financeira. 12a ed. São Paulo: Pearson Prentice Hall, 2010.

GOULART, B. Custo de Oportunidade: oculto na contabilidade, nebuloso na mente dos contadores. Revista Contabilidade \& Finanças. n. 30, 2002. p. 19-31. Disponível em: $<$ http://www.scielo.br/pdf/rcf/v13n30/v13n30a02.pdf $>$. Acesso em: 30 out. 2016.

MARTELANC, R. et al. Utilização de Metodologias de Avaliação de empresas: Resultados de uma pesquisa no Brasil. I. In: Assembléia Anual Cladea, 34. São Paulo, 2005. Disponível em: $<$ http://www.cladea.org/cladea_2005>. Acesso em: 27 ABR. 2016.

MARTINS, E. (ORG.). Avaliação de empresas: da Mensuração Contábil à Econômica. São Paulo: Atlas, 2001.

MARTINS, G. DE A.; THEÓPHILO, C. R. Metodologia da investigação científica para ciências sociais aplicadas. 2. ed. São Paulo: Atlas, 2009. 
MÜLlER, A. N.; TELÓ, A. R. Modelos de avaliação de empresas. Rev. FAE, Curitiba, v.6, n.2, 2003, p. 97-112.

RICHARDSON, S.; TUNA, I.; WYSOCKI, P. Accounting anomalies and fundamental analysis: a review of recent research advance. Journal of Accounting and Economics, v. 50, 2010, p. 410-454. Disponível em: <http://www.sciencedirect.com/science/article/pii/S0165410110000406>. Acesso em: 27 set. 2016.

ROSS, J. W. Administração Financeira. 8ª ed. São Paulo: AMGH, 2008.

SCHMIDT, P.; SANTOS, J. L. dos. Avaliação de ativos intangíveis. São Paulo: Atlas, 2002.

SILVA, J. P. da. Análise Financeira das Empresas: Ambiente da Análise Financeira, Demonstrações Contábeis Brasileiras, Análise Financeira das Empresas, Análise do Capital de Giro, Fluxo de Caixa e Projeções Financeiras, Alavancagem Operacional e Financeira. $11^{\mathrm{a}}$ ed. São Paulo: Atlas, 2012.

TITMAN, S.; Martin, J. D. Avaliação de Projetos de Investimentos. Porto Alegre: Bookman, 2010.

ZILLI, Julcemar Bruno. Valoração das propriedades rurais em Carazinho/RS e Cascavel/PR: uma análise das opções reais. Tese (Doutorado em Ciências) - Departamento Econômia. Escola Superior de Agricultura "Luiz de Queiroz". Piracicaba, 2010148 p. Disponível em: <http://www.teses.usp.br/teses/disponiveis/11/11132/tde-10022011140701/pt-br.php>. Acesso em: 20 out. 2016 